\title{
Transgender Population's Health Teaching: Reflexions on Teacher Perception
}

\author{
Bervian $\mathrm{E}^{1}$, Marques Martins LBM${ }^{1}$, Montenegro $\mathrm{MD}^{1}$, Felisbino $\mathrm{AS}^{2}$, \\ Sanches LC ${ }^{3}$ and Ribeiro ER $^{3 *}$ \\ ${ }^{1}$ Medical course students at Faculdades Pequeno Príncipe, Brazil \\ ${ }^{2}$ psychiatrist with improvement in human sexuality, Brazil \\ ${ }^{3}$ Researcher of the Health Sciences Teaching Program at Faculdades Faculdades Pequeno \\ Príncipe, Brazil
}

\section{Research Article}

Volume 3 Issue 6

Received Date: November 24, 2020

Published Date: December 24, 2020

DOI: $10.23880 /$ jqhe-16000197

*Corresponding author: Elaine Rossi Ribeiro, Researcher of the Health Sciences Teaching Program at Faculdades Faculdades Pequeno Príncipe, Rua Carneiro Lobo 333 AV IGUAÇU 333, Brazil, Tel: 41988710878; Email: elaine.rossi@hotmail.com

\section{Abstract}

This work aims to understand the perception of instructors about the teaching of trans people in health during the medical course, considering how training can influence the treatment, reception and access of these people in primary care. Twenty four interviews were conducted with professors from a Faculty of Medicine in Curitiba, Paraná, Brazil. The study of the interviews was based on the Content Analysis of Moraes (1999). It defined 5 categories of analysis: "conceptual dimension", "biological dimension", "social dimension", "pedagogical dimension" and "skills development". It is possible to conclude that the pedagogical approach during graduation presents many flaws, being necessary to show the relevance for the medical community in the sense of inserting the theme in the university's curriculum.

Keywords: Transgender; Medical School; Medical Professors

\section{Introduction}

"I see that there is a huge difference between speech and practice. In speech everyone accepts or avoids. I saw that the tutors themselves could not conceive of this (transgender), so they flee, or avoid, or make a polite speech, more or less correct, but superficial too, because they cannot discuss these issues in depth due to lack of knowledge" (D22).

The above report, regarding the introduction of topics on transgender for medical students, highlights interesting aspects of the relationship between health education and topics belonging to the LGBTQIA + community (Lesbians, Gays, Bisexuals, Transgenders, Queers, Intersex, Asexuals and More), such as transsexuality. Narratives like this, filled with ignorance about the health of the trans population, generated the purpose of this research by producing curiosity about the health care of these people and allowing the construction of the objective of this study, which is to apprehend the perception of teachers regarding health education of the trans population during medical graduation.

The beginning of the discussion on gender and sexuality and, consequently, its study, started around the 1960s, a time of libertarian contests and struggles in many parts of the world, such as the feminist revolution (1960-1970) and the sexual revolution (1960-1970). In 1968, social movements inaugurated a new period of thinking that made women and LGBTQIA + reflect their space in society. Thus, the debate and the construction of the concept of gender, biological sex, gender expression and sexuality began to be discussed and defined [1]. The Stonewall revolt in 1969 was a historic event that started the liberation of gay movements and the fight for the rights of the LGBTQIA + community. 
First, to start the discussion on gender, you must become familiar with three essential terms for the debate: sex, gender and sexual orientation. Sex is nothing more than a term used to separate men from women by a succession of biological attributes such as physical structure, external genitalia, gonads and chromosomes [2]. The concept of gender, on the other hand, is broader, as it unravels beyond physical/ bodily / sexual differences by also embracing psychosocial aspects. For the psychiatrist and researcher Stoller R, et al. [3], in his book "Sex and Gender", gender is a dynamic term with a much more psychological and cultural than biological interpretation - in this way, gender surrounds the perspective of masculinity and femininity without necessarily taking considering whether the person has a penis or vagina since gender is the way the person perceives and behaves socially, in the way of speaking, acting and dressing, for example [4].

Before discussions on gender began, the definitions of female/male were necessarily linked to biological sex, that is, at the time of birth, the individual was labeled as a man/ woman only by viewing his genitalia, which confers the gender female who is born with a vagina and male those who are born with a penis, however, the construction of what is a man/woman is not a biological fact, but a social one [5]. Finally, sexual orientation is the terminology that covers a person's sexual desire or attraction. If she is attracted to someone of the same sex, she is called homosexual, if she is attracted to an individual of the opposite sex, she is heterosexual, and if they experience desires for both sexes, they are known as bisexuals [6].

Given the basic concepts, it is possible to realize that conflicts related to gender issues are not simplistic and deserve greater knowledge. Transgender or transsexual series means a person with a gender identity other than the biological sex assigned to him/her at birth [7]. On behalf of some people, these notions of sexuality are misinterpreted and difficult to work with. The term, until recently, was considered a mental disorder by the ICD (International Classification of Diseases), with depathologization only occurring in July 2018. Many trans people do not seek medical care because of the stigma, prejudice, transphobia, disrespect for the social name and because some doctors do not respect the differences in individual genders, considering only the biological sex of patients - as a result, transsexuals seek health services less when compared to cis gender groups, that are individuals who have concordance between biological sex and their gender identity [8].

Trans people feel that their bodies (biological sex) are not in accordance with the way they perceive themselves, then trying to correct or adapt their condition to the image of the gender they identify with (psychosocial). Some use clothes and accessories to get closer to the gender they perceive, others, on the other hand, do hormonal treatments and even surgical procedures to feel complete [5]. Most trans individuals live on the margins of society, facing stigma, discrimination, exclusion, violence and comorbidities. They often experience difficulties in accessing basic health care, whether specific to their gender or general needs [9]; therefore, there is an urgent need to develop research and content on the particularities of this population. The interventions made by teachers during medical graduation propose reducing the barriers that already exist in serving this population that is very marginalized [10].

The gap in this knowledge, present in part of the medical profession leads professionals to commit flawed acts, which directly reflect on the care and reception of members of this community. Notably, negative attitudes and a lack of technical knowledge are reflected in the increase in cases of discrimination and violence practiced against this population segment - therefore, education is the main tool to change this scenario through the insertion and promotion of teaching about the health of transsexuals in medical graduation.

Inciting the discussion of gender at this time contributes to the training of professionals by correcting disparities in the care and care of trans people [10], after all, knowledge about the health of this population can enable doctors to break barriers of access, which cause suffering for these people. Thus, the involvement of common themes and scenarios related to transgender people in the development of medical and communication skills provide special moments for students to develop general skills for the appropriate use of terminology, social name and other particularities in the care of these people, generating a safe support environment to ensure they are prepared when they graduate [11]. Given that, the following research question was elaborated: "What is the perception of the professor of the medical course regarding teaching about the health of the trans population during graduation?".

\section{Method}

This is a descriptive study with a qualitative approach. Participants of this research were professors from the medical course of a private college with courses in the health area (biomedicine, nursing, pharmacy, medicine and psychology) in the city of Curitiba, Paraná, with 24 interviews, a number obtained through the division of teachers over the first four years of the course, excluding boarding school. The study sample was obtained by 3 professors from each period divided into: a representative of the tutorial moment, one from the IEC module (Teaching and Community Integration) and another from the HMC (Medical 
Skills and Communication).

All respondents were selected at random by drawing lots based on a list made available by the institution with the name of the teacher, module taught and related period. All eligible participants were invited to participate freely in the research and signed the Free and Informed Consent Form.

The interviews were conducted on the premises of the educational institution by one or more authors of this work, being individualized, in a reserved and appropriate place in order to guarantee anonymity and privacy during data collection. A semi-structured script followed, and the interviews were recorded by electronic equipment, with the interviewees due authorization and, subsequently, transcribed in full. To avoid any embarrassment and preserve confidentiality, the real names of the teachers interviewed were replaced by the letter D for "teacher" followed by a numeral that designates the order in which the interview was conducted.

The following script was adopted as a guiding instrument: 1 . What is your understanding of the "trans person"? 2. What are your considerations about teaching the health of the trans population during medical graduation? 3. What themes, subjects, concepts do you believe should be included in the medical curriculum?

This research respected the ethical principles established by Resolution 466/2012 of the National Health Council that deals with research with human beings [12]. The research was approved by the CEP (Ethics and Research Council) of FPP (Faculdades Pequeno Príncipe) under Opinion No. $3,378,214$, according to the specifications that regulate research with human beings.

\section{Presentation and Discussion of Results}

The content analysis of the data collected in the interviews was recommended by the assumptions of Moraes $\mathrm{R}$, et al. [13]. According to the author, the analysis made after the systematic descriptions help reinterpreting the messages and to reach an understanding of their meanings at a deeper level than one would have with a common reading, and his theoretical thinking goes from the preparation of the information collected by interviews with subsequent unitarization or transformation of responses into units, being grouped in relation to their common content, what the author calls categorization. Following the path of content analysis, the information is interpreted in such a way that it is not limited to the description of the content generated in the interviews, but to achieve an in-depth understanding of the messages through the perspectives of the responses to the existing theoretical knowledge.
To avoid embarrassment and preserve confidentiality, the real names of the interviewees were replaced by the letter D for "teacher" followed by a number referring to the order of the interview. These research participants, being $71 \%$ female and $29 \%$ male, were characterized according to age between 29 and 55 years, years of teaching experience between 1.5 years and 29 years, and specialty in molecular biology, even cardiovascular surgery.

Given the information obtained in the interviews with the teachers, it was necessary to categorize (grouping of content considered common among them) based on the interpretation of the respective responses. For the analysis, the categories were defined that encompassed thematic dimensions based on the theoretical framework presented, with the objective of schematizing the approaches and the research paths mentioned by them. In this sense, the thematic dimensions addressed in the teacher perception regarding health education for the trans population are:

- Conceptual dimension: includes the definition of transgender or trans person.

- Biological dimension: it concerns the sexual determinants of a transsexual defined biologically by sexual characteristics and reproductive organs.

- Social dimension: refers to the male or female behavior of a trans person according to socio-cultural issues.

- Pedagogical dimension: it exposes gaps found in the training of doctors during undergraduate courses regarding health care for transgender people.

- Skills development: brings what can be addressed on topics, subjects and content that increase and add to the development of medical skills, knowledge and attitudes toward trans people.

\section{Conceptual Dimension, Biological Dimension and Social Dimension}

Naturally, the first three categories interact with each other and the interview responses are intertwined in more than one of them. The spheres of knowledge aim to identify the central concept (s) of understanding what teachers perceive about the trans population. It was shown that most interviewees failed to arrive at the definition of transgender according to the WHO (World Health Organization) [14], but that all presented concepts that were similar and approached this basic definition. Thus, it was observed that teachers were faced with a vacuum in their knowledge about the definition of trans people. D11 and D19 demonstrate the difficulty they had in developing the concept:

"Wow... how difficult to answer that conceptually." (D11)

"Look, I will confess to you that my understanding is negligible." (D19) 
When analyzing medical training for health care for the trans population, it is evident that the approach to issues related to sexuality and gender, broadly, are not covered by the curriculum matrices. Coleman, et al. [15] states that there is little instruction on sexuality and sexual health in medical schools, creating insecurity in these doctors and in medical students when exposed to real situations of care and technical knowledge that involve these topics. Therefore, some interviewees end up running into biological definitions, merely simplistic, such as D1 that uses the karyotype, arrangement of chromosomes, to define trans while D6 uses the phenotype, the expression of genes:

"[...] she does not identify with this chromosomal sex and then she starts to want to identify herself differently." (D1)

"[...] people who have a mismatch between gender and ... wow, I do not know the definition ... between gender and phenotype, maybe." (D6)

When trying to define transsexuality using sex chromosomes, $\mathrm{XX}$ or $\mathrm{XY}$, the participant demonstrates knowledge only of the binary concept of male and female, denying other expressions of biological sex, such as intersex states. Remember that there are other manifestations, such as ambiguous genitalia, $\mathrm{X} 0, \mathrm{XXY}$ and insensitivity to androgens, which also do not fit the simplistic concept of binarism and are observable in humans. Regarding the genetic bases in the biological determination of sex, we have "Although decades of speculation have occurred, suggesting a biological or genetic basis for transgenders, little evidence has been found to support these theories" [16].

The notion of gender is something plural and versatile, being the result of a social construction, therefore, society and the historical moment in which it is inserted are constantly influencing factors in the definition of what it is to be female and male [1]. For D17, this socio-cultural understanding is revealed in his interview when he maintains:

"[...] the difference not only in the separation between genders, but also within the tasks, the roles, than what is expected of the person within the standards that are expected." (D17)

The definitions end up intertwining between biological and social relations: "As social influences are not totally visible, it seems to us that the differences between men and women are 'natural', biological, when, in fact, good part of them is influenced by social interaction" [5]. When analyzing the person beyond biological sex, Winter S, et al. [9] adjusts the definition of transgender person as one who experiences the discrepancy between his biological sex, attributed at birth, and his personal sense of gender identity, meeting the participant's understanding D8:

"... a person who does not perceive himself within the biological sex with which he was born, he perceives himself in the other sex." (D8)

\section{Pedagogical Dimension}

When asked about teaching content about the health of the trans population during medical graduation, all respondents mentioned flaws in the approach to this theme, whether in a broader or more specific context.

"[...] this teaching is very poor, which is a topic that we do not usually address ..." (D6)

"I think it is not addressed, I think it is importantly to be addressed ... there are several aspects of health that are not taken into account." (D7)

"Failed. Extremely flawed. I don't think there is, at any time they are inserted as a population to be studied ..."(D21)

The excerpt of the statements exposes the conditions that most medical schools are in when it comes to sexuality and gender. According to a survey by Obedin-Maliver, et al. [17], the time dedicated to content related to the LGBTQIA + community is, on average, 5 hours compared to the entire workload during medical graduation (around 8 thousand hours). For the author, the number of hours required in the curriculum, as well as the number of topics related to the LGBTQIA + population varies widely among higher education institutions, as there is nothing defined about what and how to approach such a subject. This can be justified by the way in which the theme is treated by the DCNs (National Curriculum Guidelines) of the Undergraduate Course in Medicine in a generalized way. In the 2014 Guideline [18], Resolution number 3 , for example, questions about gender and sexuality are cited generic to meet contemporary medical education:

"In Health Care, the undergraduate will be trained to always consider the dimensions of biological, subjective, ethnic-racial, gender, sexual, socioeconomic, political, environmental, cultural, ethical and other aspects that make up the spectrum of human diversity that individualize each person or each social group, to realize [...] I - Universal access and equity as a right to citizenship, without privileges or prejudices of any kind, treating inequalities with equity and meeting-specific personal needs, according to priorities defined by vulnerability and risk to health and life, observing what determines the Unified Health System (SUS) ".

For Negreiros, et al. [19], medical training should contribute to the understanding of the plural context, cultural diversity, ethical and humanistic dimensions, developing doctors with attitudes and values oriented toward citizenship 
- which is in accordance with the DCNs - however, it is not the that teachers demonstrate about their training:

"[...] my own training, in fact the approach was practically zero [...] we still have little training, I think that education in general fails in this sense because we hardly go beyond definition, when it comes to the definition ... [...]"(D23)

Starting the discussion of gender during medical graduation helps correct disparities in the care and attendance of trans people [10]. It is worth mentioning that continuing and permanent education is a valuable tool for this update of health professionals meeting demands that were not met during graduation. With this objective, in 2011, the Ministry of Health launched the National LGBT Comprehensive Health Policy course, online and free of charge, with the objective of fully promoting the health of the LGBTQIA + population, contributing positively to the elimination/reduction of discrimination and institutional prejudice, in addition to consolidating the universal, comprehensive and equitable system of SUS (Unified Health System) [20].

This national policy was a milestone in the achievement of health care in the LGBT community by SUS, contributing so that other social policies being guided and new strategies must be seen to face discrimination based on sexual orientation and gender identity [20]. For the authors, the strengthening of the social participation of the LGBTQIA + population in public policies also stands out, since social movements of trans people have also gained visibility after the National LGBT Comprehensive Health Policy.

"The campaigns developed by the Ministry of Health also contributed to deconstructing the stereotype of this population, allowing society, health professionals and managers to look at a new perspective, reflecting on their welcoming and health care practices. it is worth mentioning that the partnership with the LGBT movements in their plurality was decisive for the advances achieved and for the construction of a real concept of participative management, for a more inclusive, more equitable, more humane, universal and integral SUS, as stated in our Charter Magna and the laws that govern public health in Brazil " [20].

Along with the flaw in the pedagogical approach, all respondents showed how important it is for the training of general practitioners to include these contents in the curriculum of educational institutions:

"So I think that within medical education it is important that we talk about the subject, that we bring it, that we put it as knowledge" (D1)

"It would have to be institutionalized first of all in curricula" (D17)

\section{Skills Development}

Competence is a word used to qualify a person who is capable of accomplishing something [21]. For Le Boterf, et al. [22], competence implies knowing how to raise awareness, integrate and transfer knowledge, resources and skills, in a given context. Competence can only be developed in a given scenario, and the context used here is that of health knowledge.

Medical education experiences a process of transformation in its curricular bases. According to Nogueira, et al. [19], current medical training is based on techno-scientific models, and currently this model has been guided by ethical-humanist projects that end up dismantling the consolidated medical curricular structures. This transformation improves training and develops a medical graduate capable of dealing with real problems in Brazilian society [23] - for this, medical schools should develop individual and collective skills of their students according to this transformation.

For Dubin, et al. [11], medical education improves attitudes and awareness about transgenders, providing unique knowledge and clinical concerns for these people, developing skills to provide competent care, and tools to address inequities characteristics of this population. At this point, D4 highlights his concern in the whole biopsychosocial sphere of trans patients and his approach during graduation:

"The health of the LGBT population has to be addressed, health in different contexts ... the family environment of the trans population, the maternity of the trans population, the diseases that involve the trans population, the social interaction of the trans population ..." (D4)

The researcher also stresses the need for doctors to be properly trained to provide the necessary assistance to these people.

Since 2001, there has been a growing curve in the publication of research and studies on gender relations and individual and collective medical care for transsexuals.

The acquisition of these skills during medical graduation can improve the learning of specific scientific and technical subjects, such as hormone therapy, sexual reassignment surgeries, prevalence of dysphoria, depression and anxiety in transsexuals, association of dyslipidemias with the use of estrogen and erythrocytosis with testosterone, screening for breast cancer and osteoporosis among others [24], in addition to having the role of improving the basic humanistic knowledge of the proper terms, concepts, definitions and reception of this population. 
Thus, D8, D16 and D23 concentrate these conformations in their narrations:

"[...] they usually have a great deal of emotional suffering and I think that is not yet addressed in graduation.

We know that it is not a disease, but that it needs to be properly guided by trained health professionals"(D8)

"I think that since the question of understanding what gender identity is, sexual orientation, what characterizes the trans population [...]" (D16)

"[...] reframing, either by using surgery, or using hormones; to know the legislation regarding this, I think it is super important, the rights of the trans person within the health area 'do she have the right to surgery?

'Are you entitled to hormones?'At what age is this important?'I think the delimitation of age is essential too, there is a discussion nowadays about inhibiting puberty, blocking hormonal, delaying puberty, this is allowed, no, there are devices for that, these are issues we are faced and we often do not know very well what to do." (D23)

The professors interviewed in this study have a variety of more than 19 specialties, including cardiologists, intensivists, surgeons and infectologists, which highlights a wide variety of suggestions for teaching content on the topic related to the health of the trans population be addressed at graduation.

Among them, we can list the approach of terms, concepts and definitions about transgenders, as well as details that constitute the clinical interview and medical communication in the social, psychological and ethical approaches involved in health care, from the family context to the context, these populations are inserted. Content such as diversity, sexuality, motherhood, empathy and mental health was also suggested by the teachers.

Technical issues, covering medical practice, were also raised by respondents such as: the gynecological examination of trans men and trans women with a vagina, screening for cancer of the uterus, ovaries, breasts and prostates in this population, STI (Sexually Transmitted Infections), endocrine demands (hormonization and use of hormone blockers), sexual reassignment surgery, emergencies and trauma - since it is a population that suffers more violence and homicide due to their sexual and gender orientation.

The statements of D2, D7, D10 and D21 develop the subjects to be contemplated during the graduation guided by the light of their realities and specialties:

"[...] the situations of emergencies, of trauma, where at every moment we have a greater number of people who are victims of some type of violence due to their sexual orientation, so I think we have no way to escape it". (D2)

"Hormonal replacements, you know, the consequences of hormonal replacements ... [...]" (D7)

«The concept of gender, the difficulties of understanding in the community, the issue of gynecological examination, the examination of genital organs, posture, difficulties, ethical discussion.» (D10)

"[...] I think you have either taught, or inserted, this way of physical examination and anamnesis; mainly the gynecology and obstetrics [...] part I think that there is still an important psychiatric part in the follow-up [...] untreated as a mental illness, but in relation to the support [...] for them the toxicology part and infectious diseases too, they must be inserted as a population up to the part of STIs [...] "(D21)

It is considered that the categories listed: "conceptual dimension", "biological dimension", "social dimension", "pedagogical dimension" and "skills development" could build knowledge by providing the potential and vulnerabilities of the subject's education in the medical field.

It is crucial to note that teachers agree with the need to talk more about the topic and many take the position that they do not understand the subject. They admit the lack of content on medical issues involving transgenders during graduation, assuming the importance of appropriating these issues. It is configured, therefore, as a unique opportunity to recognize the structural failure of the curriculum and to transpose the paradigm that surrounds the subject.

It is necessary to promote teaching about basic concepts that strengthen the understanding and acceptance of this population, breaking the cycle of maintenance of erroneous concepts - mentioned several times during the interviews - and, if heard by a trans person, would bring discomfort, feeling of not belonging. The doctor-patient relationship would remain tangential to the reception, a premise of SUS. Another point to be considered is that many professors, in their speeches, remained only in health care, forgetting the emotional and empathic aspects that also figure between and in care.

Primordial concepts such as biological sex, gender and sexual orientation should be clarified, for example, during graduation, as these professionals, when building such knowledge, would become more empathic with the trans population that - in theory - should enjoy the your services. It is worth mentioning that the fear of prejudice and lack of understanding are one of the biggest reasons that lead the trans population not to seek medical care. In view of this, if there is systematic education, it is possible to develop 
skills to address the health of the trans population globally, welcoming this community that is often marginalized.

\section{Final Considerations}

By revisiting the objective established in this study, to apprehend the teachers 'perception of the health teaching of the trans population, it is possible to unveil the participants' ideas about teaching the health of this population at different levels.

The challenge faced by health professionals in appropriating the theme during graduation goes far beyond prejudice: it permeates, above all, the recognition of this population as a social being, as an integral part of society. Our society! A marginalized population exists, resists and struggles every day to be seen and perceived.

It is said that the subject cannot be tangential. The theme should be part of the Core Curriculum, thus allowing us to suggest, at first, the promotion of updating activities, of EPS Programs (Permanent Education in Health), aimed at filling the gap in the pedagogical approach during graduation. EPS presents itself as a powerful learning tool, in which learning and teaching are intertwined with everyday medical practice, being a device capable of making a positive impact on the individual and collective health of transsexuals.

Nevertheless, it is considered that the design of this study, together with the teachers' report, can be a limiting factor to understand the complexity related to the issue of human sexuality as it is restricted to only one medical school. Certainly the execution/reproduction of this study in other teaching centers and in other locations would enrich the debate. Including the perception and perspective of other teachers, even of students, could overcome this barrier, expanding results and generating future and fruitful discussions and interventions within the scope of this theme.

The main concern generated during the construction of this study precisely concerns the sphere of conceptual ignorance presented by the teachers whose ideas are rooted in social processes shaped by uncertainties and prejudices.

It is reiterated that the use of the Biological Dimension for conceptual interpretation still permeates the discourse of many interviewees, reaffirming the importance of multiprofessional and transdisciplinary scientific reflections and debates that make it possible to build new perspectives on the theme presented here.

Finally, recognizing and expanding the study in this field and promoting access to this content during graduation, in addition to providing support for future professionals to know how to differentiate gender, sexual orientation, trans and cis, are intended to reiterate the knowledge that each human being in his singularity and intangibility deserves respect, and that it is necessary to recognize such singularities not as a privilege but as a right.

\section{References}

1. Silva RGLB da, Bezerra WC, Queiroz SB de (2015) The impacts of transgender identities on the sociability of transvestites and transsexual women. Rev Ter Ocup of Univ São Paulo 26 (3): 364.

2. Peres APAB. (2001) Transsexualism. The Right to a New Sexual Identity. In: $1^{\text {st }}$ (Edn.), Rio de Janeiro: Renew pp: 282.

3. Stoller RJ (1968) Sex An Gender: the development of masculinity and femininity. In: House S, et al. (Eds.), New York: International psycho-analytical library pp: 383.

4. Melo TGR, Sobreira MVS (2018) Gender Identity and Sexual Orientation: Literary Perspectives. Health Topics 18(3): 381-404.

5. Jesus JG de (2012) Guide about transgender people, transvestite and others transgenders for opinion makers pp: 1-42.

6. Rios RR, Piovesan F (2019) The Discrimination By Gender and By Sexual Orientation. Semin Int - As Minor and the law pp: 154-175.

7. Balakrishnan VS (2016) Growing recognition of transgender health. Bull World Health Organ 94(11): 790-791.

8. Rocon PC, Rodrigues A, Zamboni J, Pedrini MD (2016) Difficulties experienced by transgender people in access SUS (Unified Health System). Cienc e Saude Coletiva 21(8): 2517-2525.

9. Winter S, Diamond M, Green J, Karasic D, Reed T, et al. (2016) Transgender people: health at the margins of society. Lancet 388(10042): 390-400.

10. De Carvalho Pereira LB, Chazan ACS (2019) The access by transgender people and transvestite on health primary attention: an integraty review. Rev Bras Med Família e Comunidade 14(41): 1795.

11. James S, Colling Sylvester H (2018) Transgender health and its current omission from medical school curriculum: medical students\&rsquo; perspective. Adv Med Educ Pract 9: 607-609.

12. Health M da (2012) National Health Council - Resolution 
466/2012. Brazil pp: 12.

13. Moraes R (1999) Content analysis. Rev Educ 22(37): 7-32.

14. Thomas R, Pega F, Khosla R, Verster A, Hana T, et al. (2017) Ensuring an inclusive global health agenda for transgender people. Bull World Health Organ 95(2): 154-156.

15. Coleman E, Elders J, Satcher D, Shindel A, Parish S, et al. (2013) Summit on Medical School Education in Sexual Health: Report of an Expert Consultation. J Sex Med 10(4): 924-938.

16. Green R (2000) Family co-occurrence of "gender dysphoria": Ten sibling or parent-child pairs. Archives of Sexual Behavior 29(5): 499-507.

17. Obedin maliver J, Goldsmith ES, Stewart L, White W, Tran E, et al. (2015) Lesbian, Gay, Bisexual, and TransgenderRelated Content in Undergraduate Medical Education 306(9): 971-977.

18. (2014) National Curricular Guidelines for the Undergraduate Medical Course. Pontificia Universidad Catolica del Peru Brasil, pp: 44.
19. Ferreira FRN de NB de O, Nascimento D de NFJI dos SPEF do (2019) Lesbians, gays, bisexual, transvestite and transsexuals health: from medical graduation to professional performance. Rev Bras Educ Med 43(1): 23-31.

20. Sena AGN, Souto KMB (2017) Advances and challenges in implementing National Policy on LGBT Integral Health. Tempus Actas de Saúde Coletiva 11(1): 09.

21. Fleury MTL (200) Building the Competence Concept. RAC, pp: 196.

22. Le Boterf G (1994) On competence - essay on a strange attractor. Broché. Paris: Editions d'Organisation. 7(7).

23. Eliane Dias G, Cristina A, Luiz M, José Renan Cunha M, Maria Emília Caixeta de Castro L (2013) Essential competences for the training and evaluation of performance in undergraduate medical education. Rev Bras Educ Med 37(4): 526-539.

24. Dubin SN, Nolan IT, Streed Jr CG, Greene RE, Radix $\mathrm{AE}$, et al. (2018) Transgender health care: improving medical students\&\#39; and residents\&\#39; training and awareness. Adv Med Educ Pract 9: 377-391. 